\title{
Chapter 8 \\ A Comparative Framework for Studying Global Ethics in Science and Technology
}

\author{
Dirk Stemerding, Virgil Rerimassie, Rinie van Est, Yandong Zhao, \\ Sachin Chaturvedi, Miltos Ladikas and Frans W.A. Brom
}

\subsection{Introduction}

Science and technology are an important source of progress as well as tension and conflict in society (Swierstra and Rip 2007). This basic assumption has been taken as a starting point in the Global Ethics in Science and Technology (GEST) project

D. Stemerding $(\varangle) \cdot$ V. Rerimassie $\cdot$ R. van Est

Rathenau Instituut, P.O. Box 95366, 2509 CJ The Hague, The Netherlands

e-mail: d.stemerding@ rathenau.nl

V. Rerimassie

e-mail: v.rerimassie@ rathenau.nl

R. van Est

e-mail: q.vanest@rathenau.nl

Y. Zhao

Chinese Academy of Science and Technology for Development (CASTED),

Beijing, People's Republic of China

e-mail: zhaoyd@ casted.org.cn

S. Chaturvedi

RIS, Zone IV-B, Fourth Floor, India Habitat Centre, Lodhi Road, New Delhi 110003, India e-mail: sachin@ ris.org.in

M. Ladikas

Centre for Professional Ethics, School of Health, University of Central Lancashire,

Brook 317, Preston PR1 2HE, UK

e-mail:mladikas@uclan.ac.uk

F.W.A. Brom

Ethics Institute, Utrecht University, Janskerkhof 13, Room 0.03, 3512 BL Utrecht,

The Netherlands

e-mail: f.brom@rathenau.nl 
for a comparative study of three different fields of science and technology. In the field of new food technologies, especially genetically modified crops, the expectations, tensions and conflicts surrounding these technologies can be documented and discussed from a historical point of view. In the new and emerging fields of nanotechnology and synthetic biology, on the other hand, we can show how more and more attempts are being made to manage expectations, tensions and conflicts in an anticipatory way.

Another basic assumption of the GEST project is that the nature of expectations, tensions and conflicts will vary, not only in relation to the contents of particular fields of science and technology, but also according to particular socioeconomic conditions, cultural contexts and values in the different global regions of Europe, China and India. Our aim in the three case studies presented in the following chapters is to better understand the ways in which the expectations, tensions and conflicts surrounding science and technology relate to the specifics of different fields and to the broader societal contexts shaping developments in these fields. This chapter presents a framework for a more detailed comparative analysis of the three fields - food technology, nanotechnology and synthetic biology —in the three regions.

In the framework that we propose, the emphasis is on societal discourses as central storylines in the case study descriptions (Hanssen et al. 2008). This focus on the discursive aspect will enable us to systematically map the expectations, tensions and conflicts arising, or potentially arising, from developments in the three fields of science and technology in the different regions. We will distinguish three discourses that are primarily defined by their specific content, namely those relating to issues of innovation, risk and power and control. In addition we will differentiate between discourses of reflective ethics and lay morality, showing how the issues of innovation, risk, and power and control are perceived, both in the context of practices of ethical analysis and in the context of wider public debate. In other words, with regard to the three content-related discourses, the discourses of reflective ethics and lay morality are both reflective and crosscutting.

The aim of our comparative analysis is, first, to highlight particular commonalities and differences between cases and regions in terms of the issues discussed and reflected upon in these various discourses, and, second, to show how these commonalities and differences can be understood in terms of the specific nature of scientific and technological fields, and in terms of particular socioeconomic conditions, cultural contexts and values in the different regions.

The focus on science and technology discourses in describing and comparing our case studies should help us address some crucial questions from the GEST project. Governments in all three regions stimulate scientific and technological innovation and seek ways to deal with potential risks and conflicts arising from new and emerging science and technology. The object of our comparative analysis is a better understanding of the history and evolution of these tensions and conflicts and to see how this understanding might be translated into more responsive and robust practices of anticipatory governance of science and technology in the three regions. More specifically we focus in the GEST project on the discourses of 
reflective ethics and lay morality as important sources of understanding that, especially in Europe and the US, have been 'mainstreamed' through the establishment and promotion of public ethics bodies, programmes on ethical, legal and social implications, and more comprehensive technology assessment practices, including various forms of public deliberation and engagement (Paula 2008; van Est and Brom 2012).

The main questions guiding our comparative analysis might thus be phrased as follows: how are the different science and technology discourses in the three regions being translated into science and technology policy-making, and how is this translation mediated by institutionalized forms of ethical reflection and public deliberation? We will present an outline of our framework by discussing:

- the nature of the five discourses that we have distinguished,

- more specific definitions of these five discourses,

- the questions that will guide our comparative analysis, including some main findings from the case studies, and

- some concluding observations about the governance implications of our comparative analysis.

\subsection{Nature of the Five Science and Technology Discourses}

We see discourses as 'frames' structuring societal debates in terms of particular ideals, concerns, rights and values that may engage actors in politics, governance and regulation. Science and technology discourses will relate, on the one hand, to expectations about innovation and the goals and problem-solving opportunities of science and technology and, on the other hand, to concerns about the risks, side effects and wider societal consequences of science and technology. Such discourses should be seen as rooted in common cultural experiences in which debates about science and technology have crystallized around particular recurrent themes and values, in terms of which scientific and technological developments can be both justified and challenged. These experiences will be framed by particular historical and 'iconic' exemplars of science and technology, figuring either as icons of progress, like electric light or penicillin, or as icons of risk, like asbestos, nuclear energy or genetic modification. These common cultural experiences refer to a historical dimension of science and technology discourses in society, which will also shape current and future discourses about new and emerging technologies.

Science and technology discourses will likewise be fostered and shaped by specific culturally embedded reflective practices in society, including ethics, philosophy, the social sciences, media and art. These two dimensions are translated in our framework into three content-related and two reflective and crosscutting discourses, as described above in the introduction and depicted in Fig. 8.1. The discourses of innovation, risk, and power and control are primarily defined by their specific content. The discourses of reflective ethics and lay morality are primarily 
Fig. 8.1 Three contentrelated and two reflective and crosscutting science and technology discourses

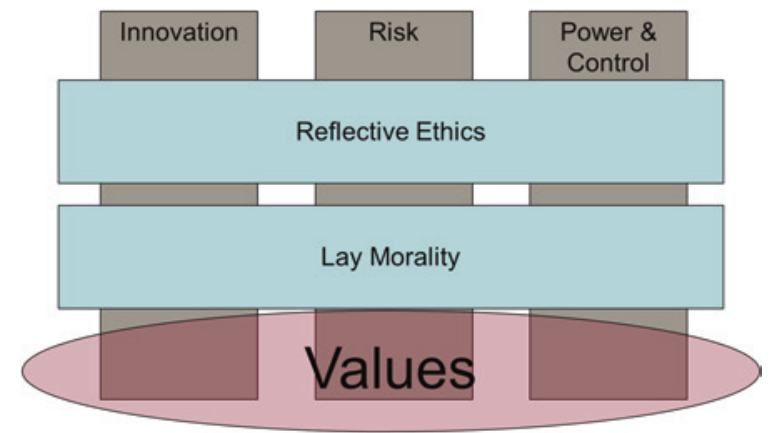

defined as reflective and crosscutting debates articulating various perceptions and assessments of the themes and values that are discussed in the other three discourses.

There are two important observations to make with regard to the use of this framework in the case studies presented in the following chapters. The historical dimension of science and technology discourses implies that these discourses are shaped by specific historical and cultural conditions and experiences that may differ from region to region. In other words, the ideals, concerns, rights and values that will inform these discourses in our case studies should be understood in the context of the specific histories and cultures of the three regions of Europe, China and India. This is also true, of course, for the reflective practices informing these discourses and the particular values that characterize public debate and science and technology policy-making in the context of different political institutions and cultural traditions in the three regions (see Chaps. 5, 6 and 7). Our comparative analysis therefore sets out to highlight, in the three case studies of the GEST project, the commonalities and differences between science and technology discourses in the context of these different and regionally specific histories, experiences and values.

As a second observation about the use of our framework, it is important to note that it has to be empirically established to what extent the different discourses can indeed be clearly recognized in describing the debates, tensions and conflicts surrounding the fields of science and technology in the three regions. Moreover, in considering these debates, tensions and conflicts, the distinctions between the different discourses often will not be clear-cut or easy to demarcate. However, by drawing these distinctions, our framework can serve as a valuable investigatory searchlight that may help us define relevant storylines in our case studies for comparative analysis.

\subsection{Definitions of the Science and Technology Discourses}

Even though the discourses that we have distinguished in our framework do not constitute sharply delineated categories, we do, of course, need definitions to work with in our case study descriptions. In the following, the five science and 
technology discourses are more specifically defined in terms of the main themes that are addressed, the values that are implicated in discussions about these themes, and the actors that are most involved in these discussions.

\subsubsection{Innovation Discourse}

The main theme of the innovation discourse is the potential benefits of investments in science and technology: that is, the ways in which science and technology may contribute to important societal aims and challenges, such as economic competitiveness, general societal progress, increasing scientific temper and more specific societal challenges concerning the environment, energy, food and health, including public health. Thus the innovation discourse sets societal agendas for science and technology policy-making and defines steps and conditions to succeed. Values implicated in these science and technology debates may include market freedoms, progress, self-reliance, sustainability, social justice (including access) and equality. The actors most involved in the innovation discourse are scientists, industry and government: that is, the parties directly involved in the 'innovation system'. But there may also be other, critical voices from more marginally involved groups, including civil society organizations.

\subsubsection{Risk Discourse}

The main theme of the risk discourse is the harm potentially caused by scientific and technological developments to health (including public health), to the environment or to individual rights such as privacy. Although there is traditionally a strong focus in governmental risk regulation on 'physical' harms to human health and the environment, societal concerns about risks often also relate to 'non-physical' harms, including wider socioeconomic and socioethical impacts in society. Values implicated in these risk debates include safety as a citizen right (i.e. the right to protection), harmony, dignity, precaution, social justice and sustainability. The actors most involved are scientists, government and regulatory agencies: that is, the parties directly involved in the 'risk governance system', which may however also include the more wide-ranging activities of public ethics and bioethics bodies and technology assessment organizations. Here again, there may be other, particularly strong and critical voices from groups outside this system, including civil society organizations.

\subsubsection{Power and Control Discourse}

In societal debates about science and technology, tensions and conflicts may arise not only within, but also between, different discourses. Such power struggles raise controversial questions about control, responsibility and participation in dealing 
with issues of innovation and risk and with the tensions between the two. The wider implications of scientific and technological developments for existing social, economic and geopolitical power relationships are another important theme in the power and control discourse, also involving questions about whose interests are served and about the ownership of knowledge and technology. Debates over power and control may involve the entire spectrum of values related to innovation and risks, including market freedoms, self-reliance, citizens' rights (to protection and choice), harmony, sustainability, global justice (access) and equality. Civil society organizations and other public voices are often especially important actors outside established systems of innovation and risk governance that may raise questions about these issues.

\subsubsection{Discourse of Reflective Ethics}

Ethics has emerged as an increasingly important topic in public debates about science and technology, stimulating reflective ethics as a crosscutting discourse involving expectations, concerns, rights and values relating to innovation, risk, and power and control (see Chap. 2). Reflective ethics may contribute to public debates by articulating ethical issues, stressing the consequences of scientific and technological developments for social values and fundamental rights, and opening up debates about new ways to align values with these developments. Thus reflective ethics may enrich or initiate ethical debate by acting as an 'early warning' system, highlight tensions between values and scientific and technological developments, and translate ethical deliberation into policy-oriented guidelines or recommendations. Reflective ethics discourses have been institutionalized in public ethics and bioethics bodies and technology assessment organizations, supporting public debate or playing an advisory role in governmental policy-making. Reflective ethics has also taken shape in research programmes focusing on the ethical, legal and social issues raised by new and emerging science and technology, and may find expression in less formalized modes of ethics deliberation, such as the media or art.

\subsubsection{Discourse of Lay Morality}

In the history of science and technology debates, we also see the emergence of a discourse more open to participation by groups or individuals that do not necessarily claim any particular expertise in the scientific subjects under discussion, but nevertheless believe or are persuaded that their voices are as valid as those of the experts in the field of science or ethics (see Chaps. 3 and 4). Like the reflective ethics discourse, this public discourse may relate to the whole range of issues and 
values relating to innovation, risk, and power and control. As a crosscutting discourse it is an important expression of what has been termed 'lay morality'. The discourse of lay morality may find expression in spontaneously emerging public debates and controversies, but can also take shape in organized forms of public dialogue or consultation, such as focus groups or opinion surveys, and, last but not least, will often be embodied in activities and initiatives from civil society organizations.

\subsection{Comparative Analysis of Science and Technology Discourses}

Our framework helps us structure the case study descriptions and analyses in two ways. It serves, first of all, as a 'searchlight', defining different discourses as relevant storylines. Thus we have examined the role of these discourses in debates and policy-making relating to different fields of science and technology in the three regions of Europe, China and India: how significant are the different discourses in shaping debates and policy-making, what are the issues and values at stake, who are the main actors involved, and which tensions and conflicts do we see within and between these discourses? In structuring the case study descriptions along these lines, the framework also facilitates a comparative analysis, guided by the following questions:

- What are the commonalities and differences between the three regions, if we compare the discourses in any particular field of science and technology?

- How are these commonalities and differences to be understood in relation to the specific socioeconomic conditions, cultural traditions, political institutions and values in the three regions?

- What is the role of the different science and technology discourses in science and technology policy-making in the three regions: that is, how are these discourses being translated into science and technology policy-making?

- To what extent and in what ways is this translation mediated by the two crosscutting discourses of reflective ethics and lay morality?

\subsubsection{Findings from the Case Studies}

The next three chapters of this book focus on developments in food technologies, nanotechnology and synthetic biology, comparing the ways in which science and technology discourses in each of these fields have evolved in the three regions (see Chaps. 9, 10 and 11). Here we present a summary of the most significant findings from this comparative analysis, guided by the GEST framework and the questions listed above. 


\subsubsection{New Food Technologies in the Three Regions}

In the past 20-30 years Europe has seen attempts to introduce genetically modified food products commercially, which has led to strong resistance from civil society organizations and consumers. As a result, genetically modified food products have remained effectively barred from the European market. In this context a risk discourse has become predominant in Europe, emphasizing the principle of precaution and consumers' freedom of choice. However, this risk debate also involves a more comprehensive value-laden tension between, on the one hand, a 'productivist' innovation discourse of industrially driven agriculture directed towards increasing levels of production through convergent applications of biotechnology, and, on the other hand, a 'post-productivist' power and control discourse aiming at more sustainable, environmentally friendly, localized and pluralistic agricultural practices, including organic farming.

For the Chinese government, food security is a core issue, and there is a basic consensus that China should catch up with developments in transgenic technology in developed countries by building up its own transgenic technological strengths in agriculture. In this innovation discourse, there is a strong emphasis on ensuring that China develops and maintains an independent ownership of its intellectual property rights in the area of genetic modification. Indeed, in terms of power and control, the food security and safety agendas are largely driven by the government, and there is very little scientific or public debate on the implementation of new technologies, including genetically modified products in the Chinese food chain. More recently, however, issues of risk related to genetically modified food products have become a focus of public concern in China.

Debates on food technologies in India highlight several challenges: food insecurity, declining productivity, the depletion of natural resources, increased risk from climate change, rising input costs, changing food habits and extremely high post-harvest losses. At the same time, debates and deliberation on issues of risk and regulation related to genetically modified foods have intensified in India, and this has led to the complete suspension of the process of commercializing genetically modified products. According to the opponents of genetic modification, such crops have negative effects on the environment and biodiversity, and also on socioeconomic conditions, as capital-intensive agriculture increases economic disparities between large and small farmers. In addition to this emerging risk discourse, we also see in India an active innovation and power and control discourse about the right balance between the various technological choices for food production: that is, transgenic technology, traditional breeding and organic farming.

\subsubsection{Nanotechnology in the Three Regions}

In Europe, many governments have promoted innovation in nanotechnology as a contribution to economic growth and competitiveness. Besides the strong and early involvement of science and industry stakeholders in this innovation 
discourse, we have also seen the early emergence of a predominant risk discourse involving a range of state, private and civil society actors. This risk discourse not only relates to technical issues of risk, but has also emerged around other topics, such as uncertainty and precaution, with some civil society organizations calling for a moratorium on nanotechnologies. In this context, a strong power and control, and also ethics, discourse has emerged, mainly driven by philosophers, social scientists and civil society organizations, emphasizing the socioeconomic and socioethical dimensions of nanotechnology. Several expert ethics bodies and technology assessment institutions in Europe have been conducting ethical assessments of nanotechnology. Nanotechnology has not become a big public issue in Europe-not yet, at least-but there have been various experiments in public engagement.

In China there is a clearly predominant innovation discourse highlighting, as in Europe, the potential of nanotechnology to foster economic growth and global competitiveness. Although support for this pursuit of progress and 'leapfrog' development is widespread in China, the scientific community there has been active in putting issues of safety on the research agenda at an early stage. There have also been recommendations from within the scientific community for more transparent working methods, strengthened self-regulation and improved relations between science and society as important conditions for a harmonious innovation process. The thematization of broader, socially and ethically ambivalent aspects of nanotechnology is mostly limited to a closed community of Chinese scholars, but the first structures of a genuine ethics discourse are emerging in scientific circles. Moreover, there is some research effort taking place in China on public perceptions of nanotechnology.

In India a predominant innovation discourse has also emerged, motivated by a concern 'not to miss the nanotechnology bus' and, at the same time, laying special emphasis on the enabling role of nanotechnology in solving urgent national problems and addressing the basic needs of the masses, such as clean drinking water and alternative energy sources. The risk aspects of nanotechnology have not received much attention, however. Although it was announced in 2010 that a nanotechnology regulatory board would be set up, and a committee was formed on risks and ethical issues, nothing much has happened. The power and control discourse in India comes down to 'innovate first, regulate later'. Hardly any attention is being paid to the role of the public in the nanotechnology discourse and little is being done to address ethical challenges such as that of the distribution of benefits (Beumer and Bhattacharya 2013).

\subsubsection{Synthetic Biology in the Three Regions}

In Europe, synthetic biology is basically funded as 'blue sky' research in support of market-driven development, 'smart and sustainable' growth and competitiveness. Moreover, experts have emphasized, from the very beginning, the need to address concerns about biosafety and biosecurity and broader ethical issues. 
International civil society organizations have also been critically examining synthetic biology from an early stage, not only as a new source of risk, but also as driver of the relentless global exploitation of natural resources and the communities dependent on them. In Europe, therefore, the emergence of synthetic biology immediately prompted active discourses on innovation, risk and also reflective ethics, stimulated by European funding of research into ethical, legal and social implications. Synthetic biology is regarded as having arrived at a time when the role and position of science in society are facing increased public scrutiny. In this context, governments and scientists, including social scientists, advocate the early involvement of stakeholders and the broader public in the governance of synthetic biology. In the European power and control discourse, these issues converge in the overall theme of 'responsible research and innovation'.

In China synthetic biology is also actively supported by the government, with the aim of catching up with developments in the US and Europe. More than in Europe, however, the Chinese innovation discourse involves deliberate attempts at priority setting in the framework of governmental five-year plans, in which synthetic biology has been identified as a strategic priority in the nation's applied biotechnological research, especially in the biomedical and health care field. Issues of biosafety and biosecurity have also caught the attention of scientists in China, pointing to the need for the government to match global standards of regulation laid down in international agreements, but the major concern in this context is that issues of risk and regulation should not hamper China's striving for progress in synthetic biology. In China the government is the principal agent in synthetic biology policy-making. There has not been much demand for control from scientists or the public, and systematic ethical reflection on synthetic biology is mostly lacking.

In India there is only fragmented support for synthetic biology innovation from the government, and also little involvement of scientists or other stakeholders in discourses about the field. The most concerted contribution to synthetic biology policy-making in India has come from a special task force instituted by the government, which took a broad view of the promotion and regulation of synthetic biology, emphasizing not only its potential benefits, but also the need to address safety and ethical issues and to take the public into account. In considering India's potential for innovation in synthetic biology, the task force report put the emphasis on meeting the developmental needs of the country, identifying biofuels as one of the key applications.

\subsection{Conclusion: Governance Implications of GEST's Comparative Analysis}

The GEST project has focused on the relationships between the five science and technology discourses and science and technology policy-making in the three regions of Europe, China and India. What does the comparative analysis in the 
three case studies tell us about these relationships? In general we observe a strong intertwinement and interactive dynamics between the discourses and science and technology policy-making. However, the GEST project has been interested in particular in the mediating role in science and technology policy-making of the two crosscutting discourses of reflective ethics and lay morality. As already indicated, these discourses have recently been more and more institutionalized and 'mainstreamed', especially in Europe, in response to tensions and conflicts arising from the introduction of new science and technology.

The first part of this book has discussed this emerging landscape of ethics and public discourses and their various forms of institutionalization in the three regions. What, then, can we conclude from the case studies about the role of these discourses in science and technology policy-making?

In comparing the science and technology discourses of the three regions, there is a notable contrast between Europe on the one hand, and China and India on the other. In all three case studies we see in Europe the predominance of a risk discourse that has been translated into a general regime of 'risk governance' with a strong international dimension (International Risk Governance Council 2005). In this context, the European discourses of reflective ethics and lay morality are strongly founded in a pervasive risk governance paradigm, based primarily on fundamental individual rights to protection against harm. In China and India, on the other hand, the innovation discourse is predominant in the three cases that we have described. This innovation discourse mostly translates into definitions of collective interests or needs that should guide the governance of innovation in terms of the 'common good'.

In general terms these observations suggest that in Europe more emphasis is placed on individual than community values, whereas in the other regions community values are emphasized over individual values (see Chap. 4). In the case of China, this picture is most clear-cut and also implies, in the context of China's political system, that it is the government that defines the collective interests in science and technology policy-making, without a role for public or indeed ethics debate. In India the picture is more complex. Individual rights have been secured in the country's constitution, and India has a culture of vibrant public debate, but in science and technology policy-making a reflective ethics discourse is lacking.

These observations suggest, finally, that tensions within and between the governance of innovation and the governance of risk are major challenges for science and technology policy-making — and indeed for a 'global ethics' — in all three regions. In each of the regions, however, these global ethical challenges of power and control take a different form.

- In Europe, the major challenge is to strike a better balance in science and technology policy-making between risk governance, which is the currently dominant paradigm, and a governance of innovation informed by values related to the common good and grand societal challenges.

- In China, the major challenge is to strengthen ethics and public discourses as a basis for a more participatory governance of both innovation and risk, 
preserving harmony as a core value in the face of mounting public concerns about the role and risks of science and technology in society.

- In India, a lack of risk governance is one of the important challenges. Another major challenge is how to bridge the gap in the governance of innovation between the socioeconomic needs of the country in terms of access, equity and inclusion, and the imperatives of global economic competition, which are often paramount in science and technology policy-making.

Open Access This chapter is distributed under the terms of the Creative Commons Attribution Noncommercial License, which permits any noncommercial use, distribution, and reproduction in any medium, provided the original author(s) and source are credited.

\section{References}

Beumer K, Bhattacharya S (2013) Emerging technologies in India: developments, debates and silences about nanotechnology. Sci Public Policy 40:628-643. doi:10.1093/scipol/sct016

Hanssen L, Walhout B, van Est R (2008) Ten lessons for a nanodialogue: the Dutch debate about nanotechnology thus far. Rathenau Instituut, The Hague

International Risk Governance Council (2005) White paper on risk governance: towards an integrated approach. IRGC, Geneva

Paula LE (2008) Ethics committees, public debate and regulation: an evaluation of policy instruments in bioethics governance. Free University, Amsterdam

Swierstra T, Rip A (2007) Nano-ethics as NEST-ethics: patterns of moral argumentation about new and emerging science and technology. Nanoethics 1:3-20. doi:10.1007/ s11569-007-0005-8

van Est R, Brom FWA (2012) Technology assessment: analytic and democratic practice. In: Chadwick R (ed) Encyclopedia of applied ethics, vol 4, 2nd edn. Academic Press, San Diego, pp 306-320 